$\mathrm{DOE} / \mathrm{ER} / 12117--1$

DE92 000974

\title{
CATIONICALLY POLYMERIZABLE MONOMERS DERIVED FROM RENEWABLE SOURCES
}

\author{
Progress Report \\ for Period February 1, 1991 - October 1, 1991
}

J.V. Crivelio

Department of Chemistry

Rensselear Polytechnic Institute

Troy, New York 12180-3590

October 1, 1991

Prepared for

THE U.S. DEPARTMENT OF ENERGY

AGREFMENT NO. DE-FG02-91ER 12117 


\title{
CATIONICALLY POI YMERIZABLE MONOMERS DERIVED FROM RENEWABLE SOURCES
}

\author{
James V. Crivello \\ Department of Chemistry \\ Rensselear Polytechnic Institute \\ Troy, New York 12180-3590
}

NOTICE

\begin{abstract}
This report was prepared as an account of work sponsored by the United States Government. Neither the United States nor the Department of Energy, nor any of their employees, makes any warranty, express or implied, or assumes any legal liability or responsibility for the accuracy, completeness, or usefulness of any information, apparatus, product or process disclosed or represents that its use would not infringe privatelyowned rights.
\end{abstract}

\section{Abstract}

The objective of this project is to make use of products obtained from renewable plant sources as monomers for the direct production of polymers which can be used for a wide range of plastic applications. In this report is described progress in the synthesis and polymerization of cationically polymerizable monomers and oligomers derived from botanical oils, terpenes, natural rubber, and lignin. Nine different botanical oils were obtained from various sources, characterized and then epoxidized. Their photopolymerization was carried out using cationic photoinitiators and the mechanical properties of the resulting polymers characterized. Preliminary biodegradation studies are being conducted on the photopolymerized films from several of these oils. 
Limonene was cationically polymerized to give dimers and the dimers epoxidized to yield highly reactive monomers suitable for coatings, inks and adhesives. The direct phase transfer epoxidation of squalene and natural rubber was carried out. The modified rubbers undergo facile photocrosslinking in the presence of onium salts to give crosslinked elastomers.

\section{Development of Modified Cationic Photoinitiators}

Key to the success of the technology which has been targeted in this project is the development of cationic photoinitiators capable of initiating the polymerization of the various renewable monomers which have been proposed. Since most of these monomers can be characterized as possessing low dielectric constants, they are very poor solvents for onium salt photoinitiators which are ionic materials. Previous attempts to carry out the polymerization of epoxidized oils, simple terpenes and epoxidized rubber have failed due to the poor solubility of these photoinitiators.

During the past year, two new general synthetic methods for the preparation of diaryliodonium and triarylsulfonium salt cationic photoinitiators have developed in this laboratory. These novel methods have now been applied to the synthesis of modified onium salts

The following synthetic scheme has been developed for the synthesis of diaryliodonium salts bearing long alkoxy substituents on one of the aromatic rings. ${ }^{1}$ 


\section{Scheme 1}

$\Longrightarrow-\mathrm{OH}+\mathrm{C}_{\mathrm{n}} \mathrm{H}_{2 \mathrm{n}+1} \mathrm{Br} \frac{\mathrm{KOH}}{\begin{array}{c}\mathrm{TBAB} \\ \text { toluene }\end{array}}-\mathrm{O}_{\mathrm{n}} \mathrm{H}_{2 \mathrm{n}+1}+\mathrm{KBr}$

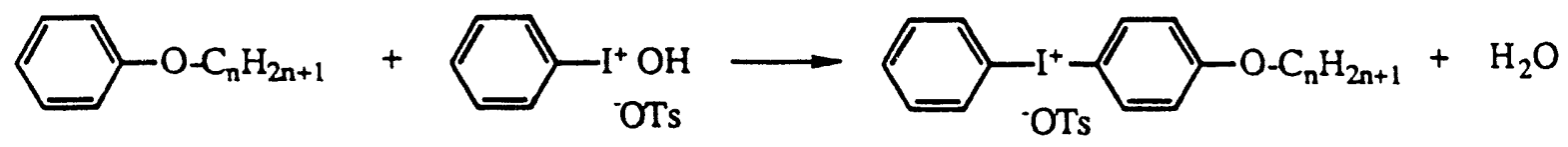

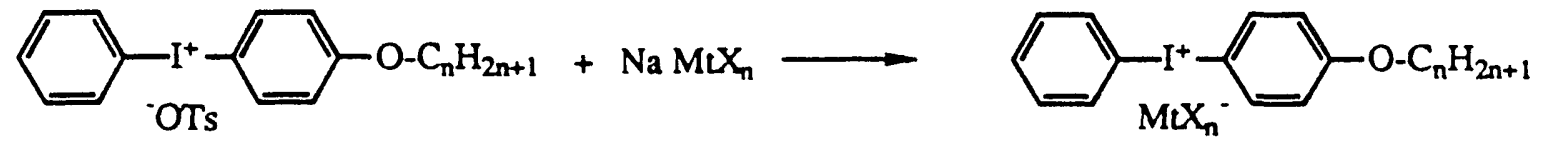

Typically, in Scheme $1 \mathrm{n}=8-18$. Using this approach, diaryliodonium salts soluble in hydrocarbon solvents such as toluene can be prepared.

In Scheme 2 is shown the new synthetic method we have developed for the synthesis of analogous triarylsulfonium salts. ${ }^{2}$ This method is especially adaptable for the prepaiation of sulfonium salts possessing long alkoxy groups.

\section{Scheme 1}

$\longrightarrow-\mathrm{OC}_{\mathrm{n}} \mathrm{H}_{2 \mathrm{n}+1}+{ }_{2}=\frac{\mathrm{CH}_{3} \mathrm{SO}_{3} \mathrm{H}}{\mathrm{P}_{2} \mathrm{O}_{\mathrm{S}}}$<smiles>CCOc1ccc([S+](c2ccccc2)(c2ccccc2)c2ccccc2)cc1</smiles>

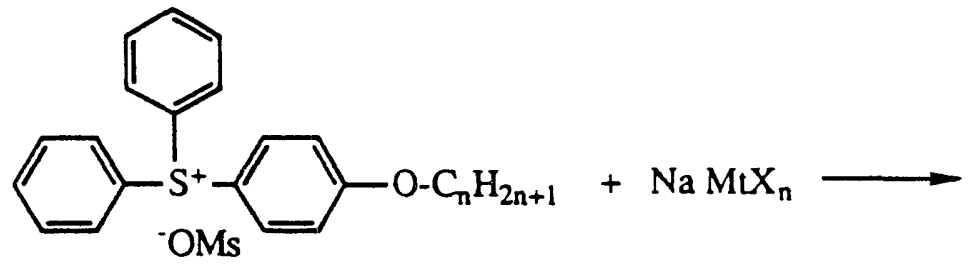<smiles>[Y16]c1ccc(OCCC)cc1</smiles>

The above synthesis proceeds smoothly at room temperature and gives nearly quantitative yields of the desired triarylsulfonium salts. 
Using the methods described in both Schemes 1 and 2, a number of photoinitiators were prepared for use in this project. The structures of these compounds are given in Table 1 . In addition to a number of salts in which the length of the alkoxy chain was varied, salts with different anions were prepared. All of the onium salts included in Table 1 were shown to be photoactive and to function as excellent photoinitiators in test cationic polymerizations with such polar monomers as cyclohexene oxide. Also included in Table 1 are the results of a brief solubility study for the various photoinitiators. As mentioned previously, solubility is of paramount importance for the efficient polymerization of the monomers and oligomers which will be investigated during the course of this project.

It should also be mentioned, that in addition to the excellent solubility of diaryliodonium and triarylsulfonium salts bearing long chain alkoxy groups, additional benefits were also realized. For example, those diaryliodonium salts bearing alkoxy groups with more than eight carbon atoms are nontoxic. Whereas the unsubstituted salts have $L_{50}$ values (in rats) of $40-60 \mathrm{mg} / \mathrm{kg}$, the latter salts were found to have $L_{50}$ values greater than $5000 \mathrm{mg} / \mathrm{kg}$. This information is of particular importance when both worker safety and potential applications involving food contact are considered for this technology.

\section{Botanical Oils}

Among the most widely distributed natural products available in nature are the botanical oils. Plants, animals and many microorganisms store energy in the form of lipids for use during periods of stress. Historically, man has harvested such oils for his own use and has purposefully domesticated plants which give high yields of edible oils. Modern agriculture produces some of these oils in large tonnages. For example, soybean oil is a commodity material produced in the United States which has a current average selling price of $\$ 0.20$ per pound. It is difficult to find less expensive organic 
starting materials for use as a substrate for chemicals and plastics synthesis than botanical oils apart from simple petroleum hydrocarbons. Indeed, considerable effort has been expended in attempting to find industrial uses for these substrates. For example, epoxidized soybean and linseed oils have found a limited market as stabilizers and plasticizers for poly(vinyl chloride). Moreover, the technology to carry out epoxidations of botanical oils on a commercial scale has been thoroughly worked out and is practiced by a number of chemical companies. The average cost for epoxidized soybean oil is \$0.50-0.75 per pound making it a highly attractive substrate for a wide variety of commercial applications ranging from coatings and inks to adhesives.

Other botanical oils which are obtained from different plant sources have a wide range of structures which vary both in the number and positions of the double bonds as well as the length of the unsaturated carboxylic acid residues present in the triglycerides. These oils potentially provide a diverse source of materials with a wide variety of mechanical and chemical properties. With this analysis in hand, we sought to explore the possibility of carrying out photoinduced cationic polymerizations with these epoxidized oils.

As a starting point, we focused our attention on the commercially avail able epoxidized soybean and linseed oils. The presence of six and nine epoxy groups per molecule, respectively for epoxidized soybean and epoxidized linseed oil suggested that they might be interesting monomers for use in photoinitiated cationic polymerization. Initial attempts to carry out the cationic photopolymerizations of these substrates using either unsubstituted diaryliodonium or triarylsulfonium salts failed to give any visible polymerization on irradiation with UV light. Examination of the reaction mixtures revealed that the photoinitiator was very insoluble in these oils. Attempts to introduce the photoinitiator into the oils by adding it in solution in a good solvent similarly failed due to immediate precipitation of the onium salt. In contrast, when (4octyloxyphenyl)phenyliodonium hexafluoroantimonate was 
employed as a photoinitiator, it was found to completely dissolve in the monomer and when irradiated, to give excellent, clear, crosslinked films. A similar result was obtained when diphenyl(4decyloxypheny)sulfonium hexafluoroantimonate was employed as the photoinitiator. This process is depicted in the following equation.

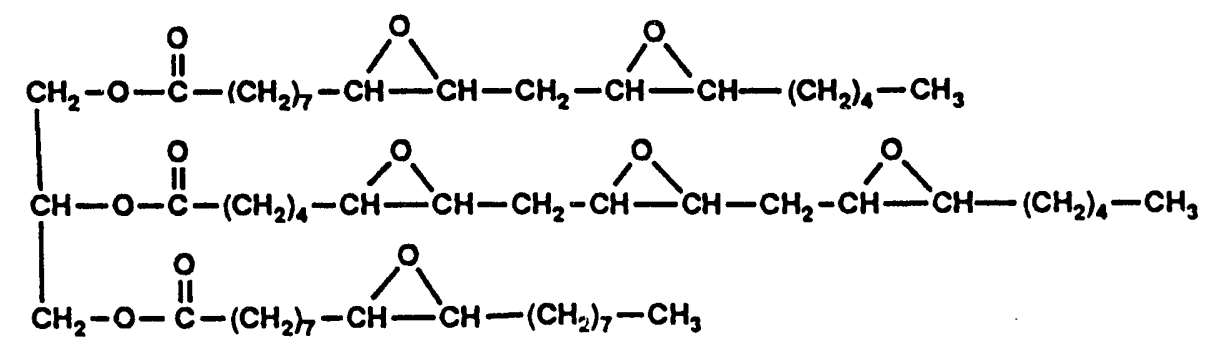

Epoxidized Soybean Oil

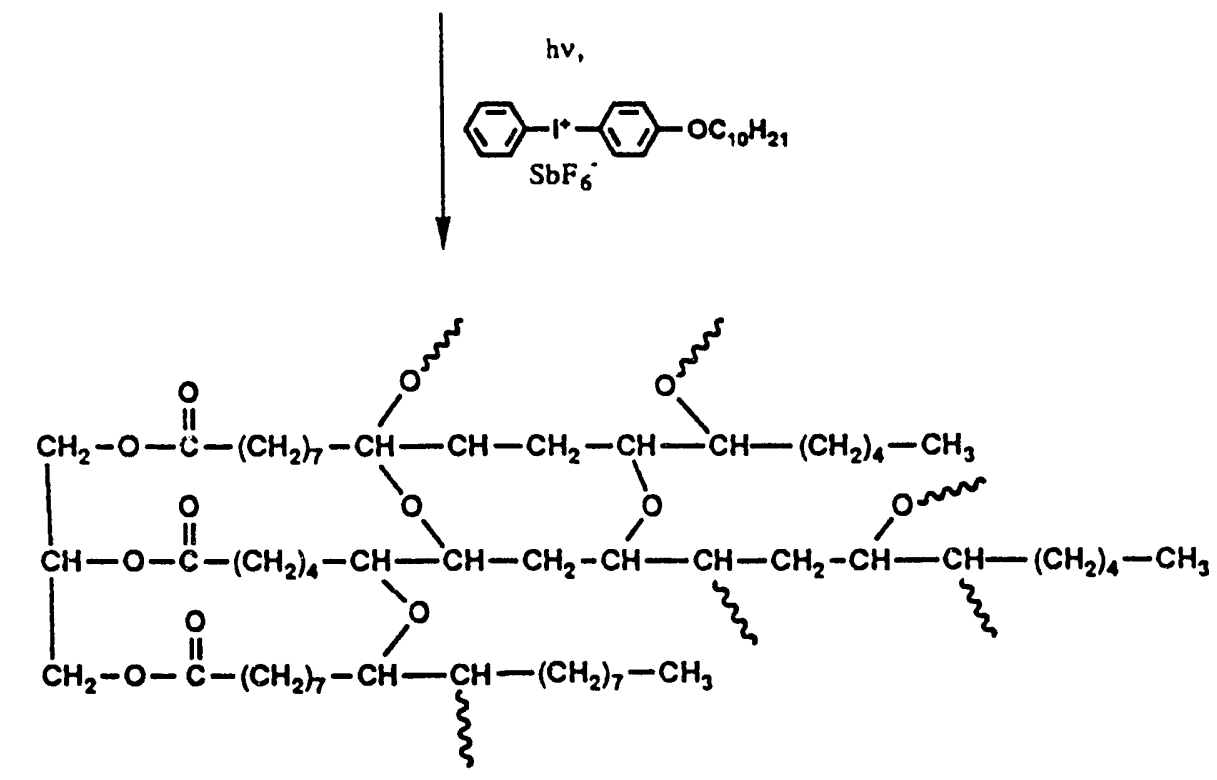

Shown in figure 1 is a photocalorimetric study of this polymerization which was conduced using the newly installed Perkin-Elmer DPC-7 Differential Photoscanning Calorimeter. This study was performed at $40^{\circ} \mathrm{C}$ using a $1 \%$ solution of (4decyloxyphenyl)phenyliodonium hexafluoroantimonate in epoxidized soybean oil. The irradiation using a $100 \mathrm{~W}$ unfiltered medium pressure mercury arc lamp was started after a 0.5 minute equilibration period. As the curve shows, rapid, exothermic 
polymerization ensues immediately on irradiation with the rate reaching a maximum after 0.13 seconds. The entire polymerization is complete after approximately 1.5 minutes irradiation. It should be noted that such polymerizations display considerable postcure effects. This is manifested in considerable dark polymerization which can be observed when photopolymerization is incomplete after irradiation but goes to completion on standing in the dark. Further DPC studies are in progress to evaluate all of the epoxidized botanical oils reported in this project.

Based on this initial success, a preliminary cure study was carried out to determine the reactivity of two different epoxidized oils. Shown in Figure 2. is a comparison between the reactivities of commercially epoxidized linseed oil and soybean oils at various photoinitiator concentrations. As noted in the figure, one mil films can be cured at excellent line speeds of up to $150 \mathrm{ft} / \mathrm{rain}$ using this photoinitiator.

Because of the higher epoxide content, the epoxidized linseed oil is more reactive than the soybean oil. In both cases, excellent flexible films were obtained on curing the two epoxidized oils which appear to have considerable promise as coatings. There appears to be a linear relationship between the level of photoinitiator concentration and the tack-free time in this study. However, photoinitiator concentrations above $3-5 \%$ would appear to greatly affect the overall cost of such systems.

Recently, a new oil, obtained from the Vernonia Galamensis plant, has be n described which contains epoxide groups as isolated. ${ }^{3}$ This plant, which has its origins in Kenya, has been cultivated in this country in Arizona. Projected costs for this oil are $\$ 0.50$ per pound. Shown below is the structure of Vernonia Galamensis oil. 


\section{Vernonia Galamensis Oil}

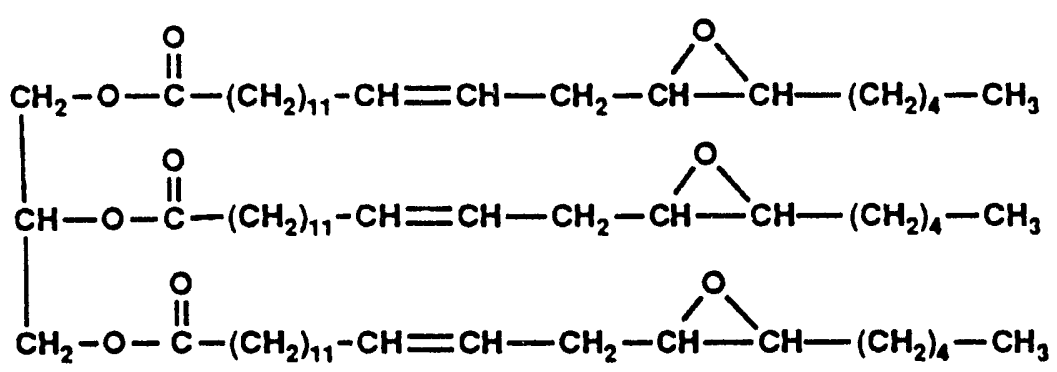

It occurred to us that Vernonia Galamensis oil might be be capable of being photopolymerized directly as isolated. Indeed, this turned out to be the case. Using either diaryliodonium or triarylsulfonium salt photoinitiators, polymerization proceeded to give clear, colorless films of the crosslinked oil. However, this oil is somewhat less reactive than the corresponding linseed or soybean oils due to its lower epoxide content. Collected in Table 2 are the data gathered from the mechanical tests performed on the UV cured films obtained from this oil.

The initial properties obtained with this oil are excellent and suggest its use in such potential applications as coil and container coatings and as adhesives. In particular, the high degree of flexibility and impact strength exhibited by these films is rather unique in UV curable coatings and suggests many additional applications. Vernonia Galamensis oil is compatible with other synthetic epoxy resins and various resins may be blended together to give a range of mechanical and chemical properties. For example, the UV cure of a 50:50 blend of Vernonia Galamensis oil and 3,4epoxycyclohexylmethyl-3',4'-epoxycyclohexane carboxylate (Union Carbide ERL 4221) produces very flexible coatings directly comparable with the pure Vernonia Galamensis oil but with a rocker hardness of 50-55.

The cultivation of Vernonia Galamensis as a new oilseed crop is actively being pursued by the Department of Agriculture. However, it is only one of several other potential sources of natural epoxidized oils. Some of these oils are also under development by domestic as 
well as international agronomic agencies as potential cash crops particularly in third world countries.

A further comparative cure study was carried out with several different commercially available epoxidized oils and derivatives and employing two different photoinitiators. Table 3 lists the materials employed in this investigation.

Samples of epoxidized linseed oil obtained from two different commercial sources were investigated having respectively, epoxide contents of 10.2 and $9.8 \%$. Epoxidized linoleic dimer acid is the DielsAlder dimer of linoleic acid containing two double bonds which are then epoxidized. Lastly, the final entry in the table consists of the glycidyl ether of a long chain alcohol derived from castor oil. In addition to the epoxide-containing substrates, two different photoinitiators whose structures are given below were used in these studies.

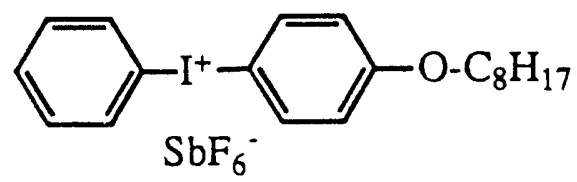

VII

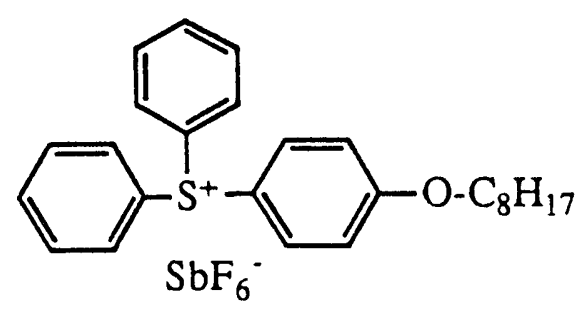

VIII

Collected in Table 4 are the data obtained in these cure studies.

Like the results shown in Table 2 and figure 2, these studies were conducted using a Fusion Systems 300W lamp which was mounted perpendicular to the travel of a conveyor system. The cure times were taken as the maximum belt speed required to give a tack-free films immediately on exiting the cure chamber. 1 mil Films of the monomer/photoinitiator were drawn onto glass slides for these tests. All the films were clear, very slightly yellow and flexible after UV cure. 
Analysis of the data contained in Table 4 shows that in concert with the results given in Figure 2, epoxidized linseed oil, (II), containing the highest epoxide content is the most reactive substrate. In addition, when the two linseed oils, (II) and (IV) are compared, the oil with the higher epoxy content $(10.2 \%)$ gives the highest cure speed. In this study, Vernonia Galamensis oil (III) exhibited a reactivity approximately comparable to epoxidized soybean oil. At the same time, epoxidized linoleic dimer acid (V) and the aliphatic glycidyl ether (VI) undergo sluggish photoinitiated cationic polymerization as expected from their low epoxide contents. Increasing the photoinitiator concentration from 1 to $5 \%$ results in a corresponding increase in the UV cure rate. It may also be noted that the structure of the photoinitiator used has little effect on the UV cure rates of these materials. This is as expected, since the quantum yields for photolysis of sulfonium and iodonium photoinitiators are very nearly the same. It may be speculated, that solubility effects may account for the differences observed.

An additional study was conducted to evaluate the effect of the length of the alkoxy side chains of a series of diaryliodonium salts on the UV cure rates of epoxidized linseed oil (Drapex 10.2). The results are given in Table 5 .

There were prepared equimolar $\left(2.87 \times 10^{-4} \mathrm{~mol}\right)$ solutions of the above photoinitiators in the epoxidized linseed oil so that a direct comparison between the salts could be made. On a weight percent basis the concentrations ranged from 5-7\%. The UV cure rates obtained for all of these diaryliodonium salts are identical within experimental error. These results were anticipated since the photosensitivity of the diaryliodonium salts are expected to be independent of the alkoxy chain length.

Vernonia Galamensis oil (III) as isolated directly fror. the seeds of the plant is clearly an interesting monomer which can be cationically photopolymerized. It should also be noted from its 
structure that this oil contains, in addition to the three epoxide groups, three double bonds. Further epoxidation of any or all of those double bonds, therefore, can lead to additional materials with different reactivities and interesting properties. Since the oil is already partially epoxidized, the cost of further epoxidations should be less than starting with a different oil which contains only double bonds and which on epoxidation gives the same number of epoxy groups.

With the object of investigating the range of properties which can be obtained from various botanical oils, a number of these oils possessing different structures were obtained. In many cases, these oils were simply purchased from the local supermarket. Other materials were obtained from the U.S. Department of Agriculture which is currently developing the plants from which they originate as potential new crops. Shown below are the structures of eight different oils, which together with Vernonia Galamensis oil, werc used in this project. 
Soybean Oil

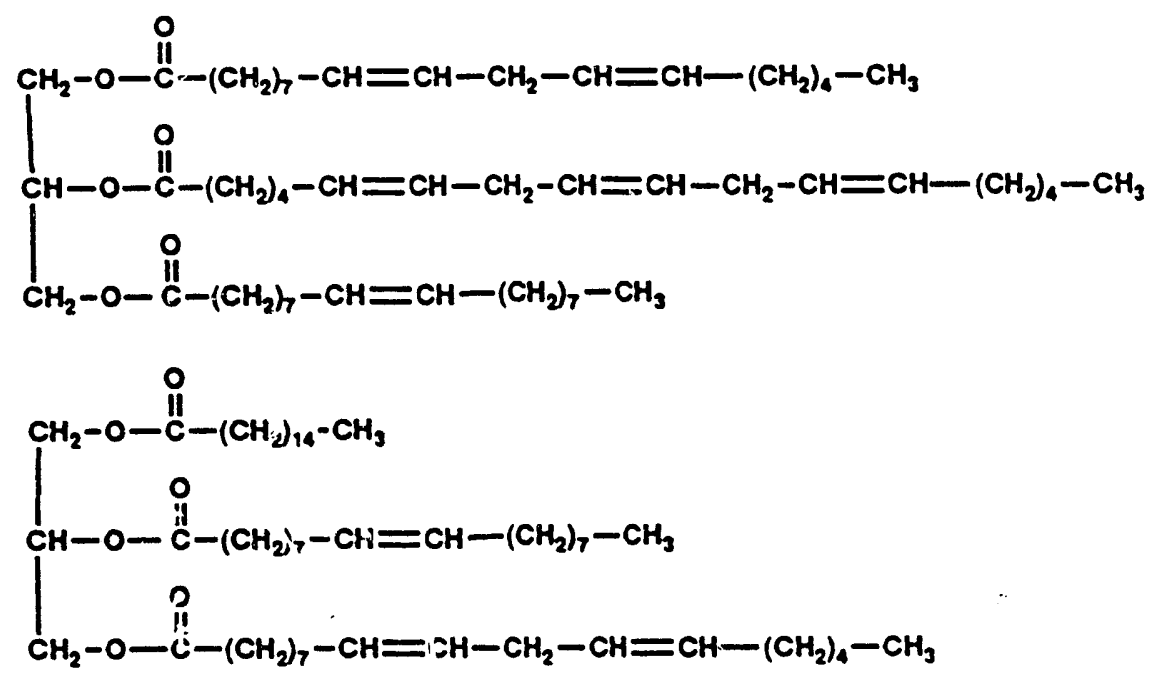

\section{Rapeseed Oil}

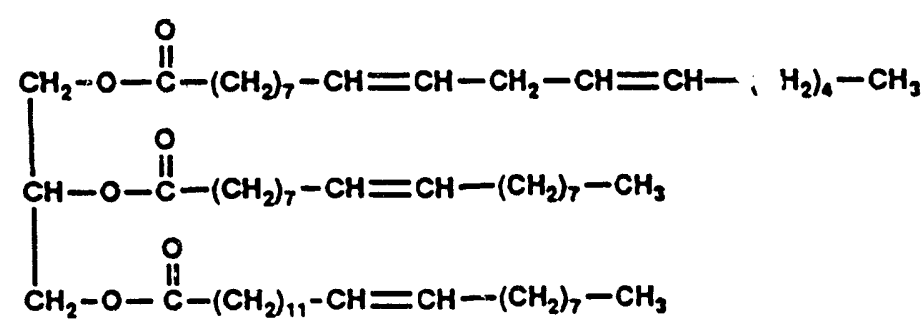

\section{Crambe Oil}

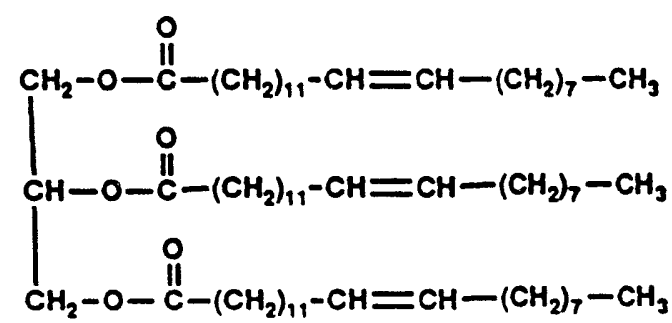


Safflower and Sunflower Oil

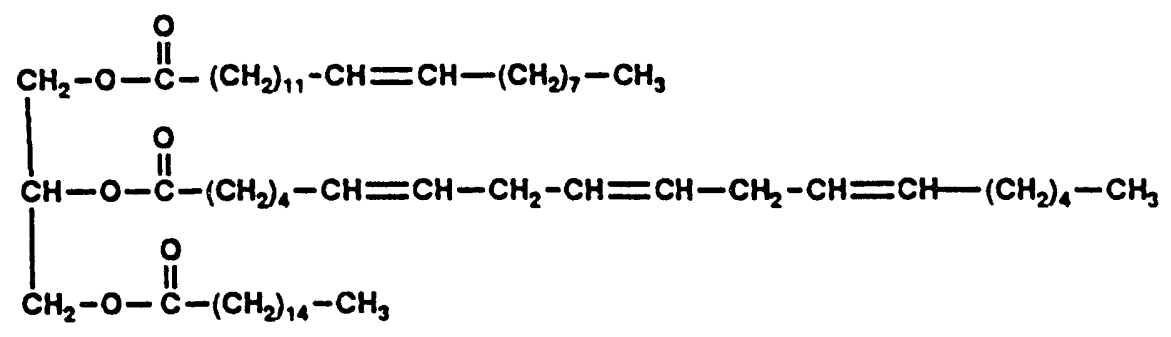

\section{Linseed Oil}

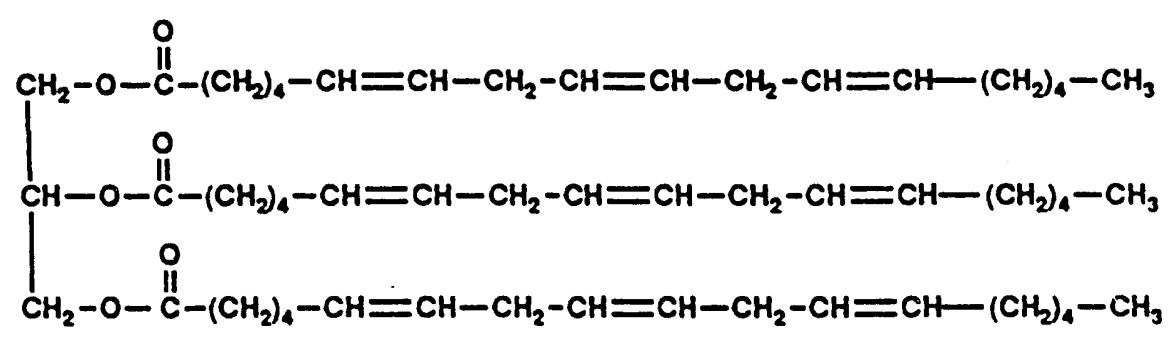

\section{Lesquerella Oil}

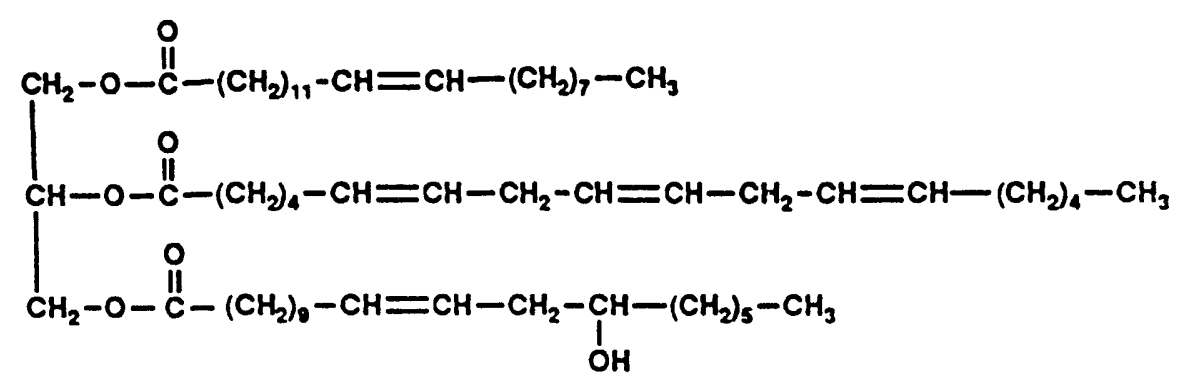

\section{Meadofoam Oil}

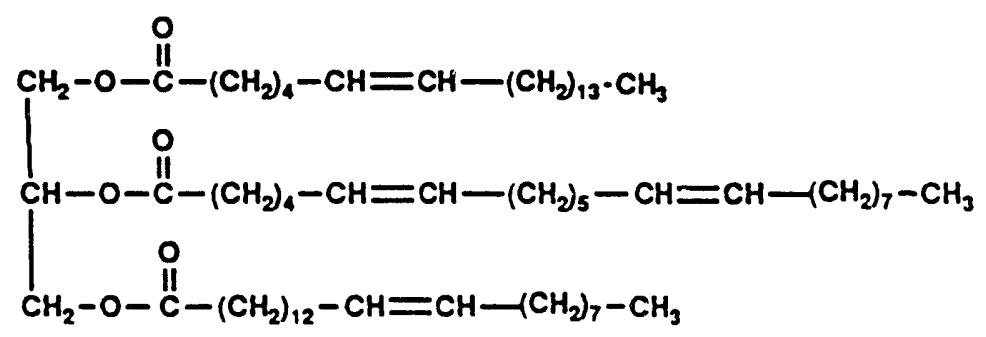




\section{Canola Oil}

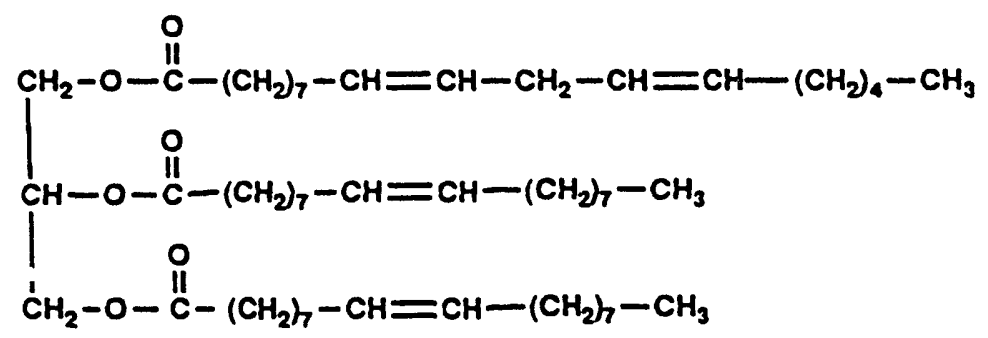

As can be seen, the oils differ from one another in several respects. Most obvious structural variations consist in the different degrees of unsaturation as well as in the placement of the double bonds. Many of the oils contain single isolated double bonds, while others contain multiple sites of unsaturation, typically containing linolenic and linoleic acid residues. Still other oils possess residues derived from mixtures of both saturated and unsaturated carboxylic acids. Of equal interest is the length of both the saturated and unsaturated chains in these molecules. It 'should be mentioned, that the above structures represent average formulae for the oils, which may vary depending on the specific plant strain grown and the actual growing conditions. Canola oil is an interesting case of an oil seed product whose structure has been genetically manipulated. It was developed from a strain of rapeseed by selective crossbreeding to possess a low content of erucic acid (13-docosenic acid).

These oils were exhaustively epoxidized using the traditional methods employing peracetic acid together with Amberlite IR-120 resin as an acid catalyst. In addition, a novel phase transfer catalytic method was also successfully employed. This method was adapted from the technique described by Venturello and D'Aloisio ${ }^{4}$ which makes use of a quaternary ammonium phosphotungstate as a phase transfer catalyst. The oxidant is commercially available hydrogen peroxide. Shown in the following equation is the synthesis of epoxidized soybean oil using this new method. 

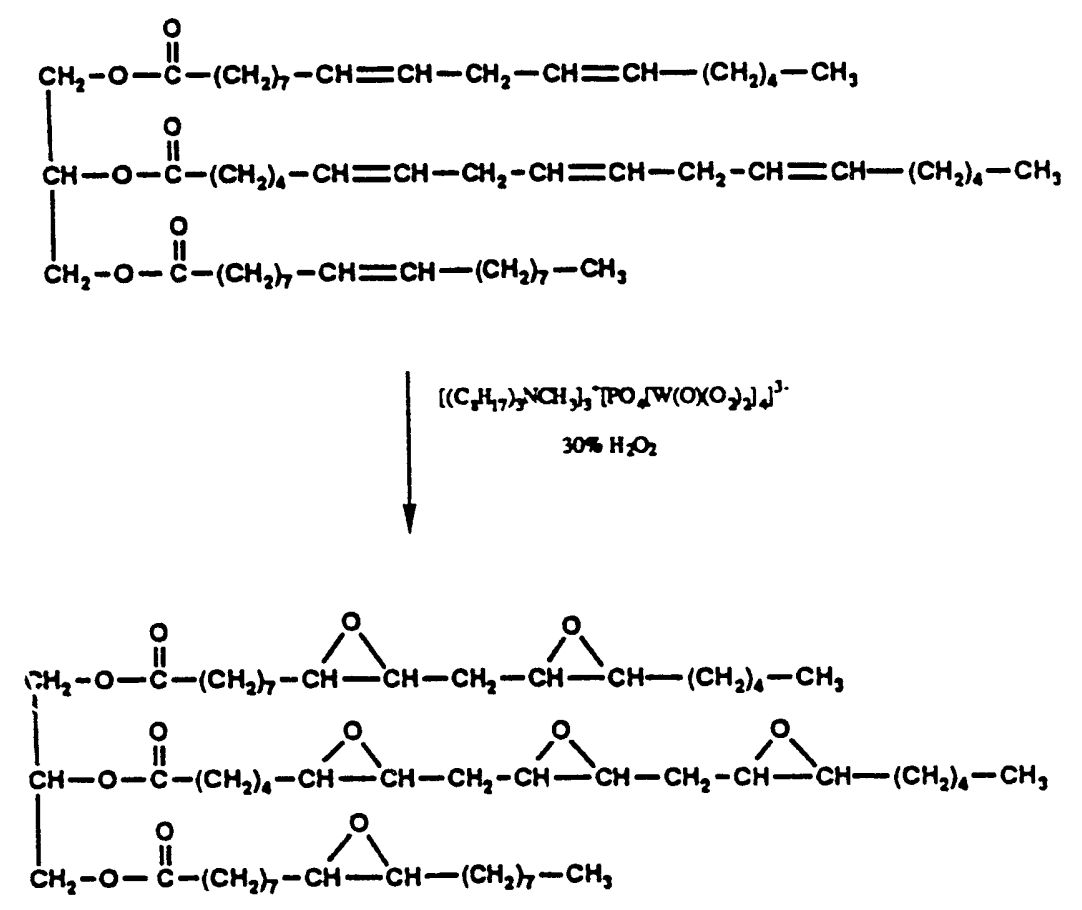

This reaction may be conveniently carried out at temperatures from $50-60^{\circ} \mathrm{C}$ in the absence of a solvent. The products are isolated by decanting the aqueous layer, and after washing with water, are ready for use as monomers in photoinitiated cationic polymerization. Using an excess of hydrogen peroxide, a quantitative conversion of the double bonds in the oils to epoxy groups is obtained. In addition to the high yields, this synthesis is advantageous because of the simple workup and the lack of byproducts of the reaction. The dilute $\mathrm{H}_{2} \mathrm{O}_{2}$ solution from the reaction is nonpolluting and may be easily discarded. The phase transfer method makes it possible to carry out a wide variety of epoxidation reactions using readily available and safe $30 \% \quad \mathrm{H}_{2} \mathrm{O}_{2}$ without danger of explosion. Previously, many epoxide monomers have been considered specialty chemicals manufactured by a few companies equipped to make and handle peracetic acid. As will be noted in the latter sections of this report, we used this method for the epoxidation of many types of unsaturated substrates.

Figure 3 shows the FTIR spectra of soybean oil before and after epoxidation. The most conspicuous change is the disappearance of 
the double bond absorption at 3000 and $1600 \mathrm{~cm}^{-1}$ in the oil before modification and the appearance of the bands at $760 \mathrm{~cm}^{-1}$ due to the epoxy groups after epoxidation. By infrared analysis, the reaction appears to be nearly quantitative. In Table 6 is shown a comparison between sunflower oil which has been epoxidized by both conventional and phase transfer catalyzed methods. In both cases, the reactions were carried out under similar conditions $\left(55-60^{\circ} \mathrm{C}\right.$ for $7 \mathrm{hr}$ ) and gave high yields of the desired epoxidized oil. Analysis of the epoxidized sunflower oil prepared by the phase transfer method showed that it typically has a higher residual unsaturation and a lower epoxy number. Further optimization of this chemistry has yet to be carried out with the object of further increasing the conversion of the double bonds to epoxy groups.

Each of the various epoxidized hotanical oils used in this study were characterized by determining their unsaturation (iodine number) and epoxide content. Collected in Table 7 are the data.

Yields obtained by both methods are typically high. Thus, $100 \mathrm{~g}$ commercial Canola oil gave $100 \mathrm{~g}(90.9 \%)$ of epoxidized oil while 75 $\mathrm{g}$ Vernonia oil gave $74.1 \mathrm{~g}(93.3 \%)$ of the corresponding epoxidized Vernonia oil. Both of these oils were epoxidized using the phase transfer method. The IR of the latter though, shows and increase in the intensity of the $\mathrm{OH}$ peak pointing to some epoxide ring-opening which occurs during the reaction or during workup. Safflower and sunflower oils were epoxidized using the usual peracetic acid technique. The FT-IR spectra of the above materials showed complete disappearance of olefinic double bonds $v_{\mathrm{C}-\mathrm{H}}$ at $3000 \mathrm{~cm}^{-1}$ and $v_{c=c}$ at $1600 \mathrm{~cm}^{-1}$. Two new peaks were seen at around $825 \mathrm{~cm}^{-}$ 1 corresponding to the epoxy groups. The amount of $\mathrm{OH}$ groups present in the oil was comparable to that of the starting oil.

Preliminary UV cure studies of these oils were carried out to determine whether the various oils could be cationically polymerized as well as to measure their rates of polymerization. The results of this study are collected in Table 8. 
The oils in Table 8 are listed in order of their increasing UV cure rates as measured by the maximum conveyor speed required to give a tack-free film immediately on exiting the cure chamber. Also listed in this table for comparison are epoxidized oils obtained from commercial sources. All of the epoxidized oils underwent facile UV polymerization. As noted before, the highest cure rates were observed for those materials having the highest epoxide number. The photoinitiator (4-octyloxyphenyl)phenyliodonium hexafluoroantimonate is soluble at room temperature in those epoxidized oils having high epoxide numbers. In oils having low epoxide numbers, the photoinitiator dissolves readily on warming the oil at $40-50^{\circ} \mathrm{C}$. The solutions which aie obtained are stable for some time, however, on standing the photoinitiator tends to crystallize out. UV cured films of the oils were clear, and highly glossy. Free standing films could be obtained by stripping them from the glass substrates using water or acetone. The quality of the films which were obtained was highly variable and can undoubtedly be significantly improved for example, by the addition of wetting agents. Free standing films are flexible and have considerable elongations. The mechanical properties of these films will be measured in a future study which correlates the structure property relationships between the various oils. UV cured films were successfully deposited on glass, wood, steel and aluminum substrates.

Since the UV cured epoxidized oils are derived from natural products, and even after cure contain glyceryl triester groups, they may be attacked by bacteria and other microorganisms and therefore may be biodegradable. To explore this possibility, several samples of films of UV cured epoxidized linseed and soybean oil were buried under 1 inch of common garden soil. After three and six months, these samples will be recovered and examined for evidence of possible biodegradation. More complete studies will be conducted for various oils at a later time when optimum cure parameters have been determined for these materials. 
Terpenes

A wide variety of simple mono, di and polyterpenes exist in nature and are present in numerous plant species. These terpenes are available today largely as byproducts of the paper and pulping industry and currently are in considerable oversupply. This oversupply has resulted in a depression of the cost of these materials. For example, terpentine (a mixture of monoterpenes) is priced at $\$ 1.40$ per gallon ( $\$ 0.16$ per pound) while rosin acids (mainly abietic acid) sell for $\$ 0.25$ per pound. Terpenes, thus, constitute a low cost source of potentially interesting monomers. We have selected the following major constituents of terpentine for study in this program.

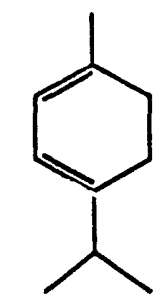

$\alpha-t e r p i n e n e$

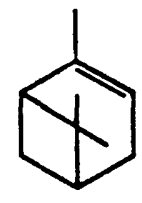

$\alpha$-pinene

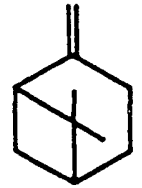

$\beta-$ pinene

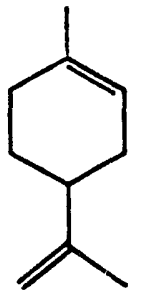

limonene

The goal was first, to determine whether the polymerization of these monomers could be carried out using cationic photoinitiators. Since these monomers have previously been polymerized using Lewis and Brønsted acids, we wished to determine whether there were any unique advantages or properties which could be obtained using photoinitiated cationic polymerization. Secondly, the same terpenes were considered as substrates for the preparation of other types of monomers which could then be subjected to cationic polymerization.

We have begun our investigation with optically active, dlimonene, which is obtained from citrus peels as well as from terpentine. The current selling price of this sompound is $\$ 0.70$ per pound. Of special interest to us is the presence of the two very different double bonds in this molecule which should have 
correspondingly different reactivities in polymerization reactions. Specifically, we wished to attempt to find conditions under which the polymerization of the exocyclic double bond would selectively polymerize leaving the endocyclic double bond intact. Ultimately, it is our aim to convert the internal double bonds of the resuling polymers and oligomers via epoxidation to the corresponding cycloaliphatic epoxides. We expect that such materials should be exceptionally highly reactive substrates in photoinitiated cationic polymerization and should be useful for many practical applications.

The polymerization of limonene was attempted under free radical conditions using as initiators, $\alpha, \alpha$-azobis(isobutyronitrile)(AIBN), benzoyl peroxide (BPO) and t-butyl peroxide ( $t$-BuPO) at initiator levels of $1.75,1.75$ and 3.1 weight percent respectively. In all three cases, the yields and molecular weights of the polymers (0.2-0.4\%) which were obtained were very low. This is in accordance with the earlier literature results reported for the free radical polymerization of this monomer. 5 Shown in Table 9 is a ${ }^{1} \mathrm{H}$ NMR analysis of the oligomeric procucts of these polymerizations in which the ratio of endo to exocyclic double bonds were determined.

In view of the overall failure of the attempted free radical polymerization of limonene, it was decided to attempt the polymerization of this terpene under cationic reaction conditions. Polymerization of limonene by a cationic mechanism using Lewis acid catalysts is well known to occur. ${ }^{6-10}$ Initially, the polymerization was conducted using onium salt cationic photoinitiators. A wide variety of alkoxy-substituted diaryliodonium and triarylsulfonium salts photoinitiators were examined for their solubility in $d$ limonene. The photoinitiator having the best solubility characteristics was found to be: 


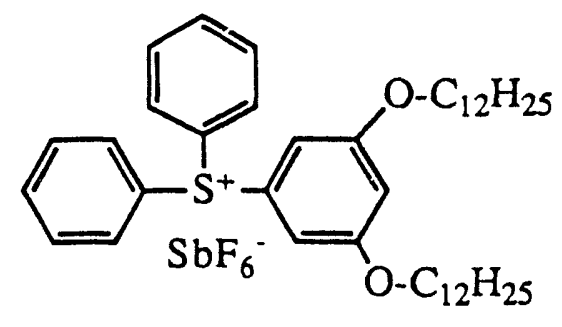

which gave homogeneous solutions in d-limonene at temperatures above $40^{\circ} \mathrm{C}$. Using this photoinitiator at a concentration of $1.6 \times 10^{-1}$ molar $\left(1 \%\right.$ by weight), polymerizations were carried out at $50^{\circ} \mathrm{C}$ by irradiation in quartz tubes in a Rayonet Photochemical Reactor. The products were poured into methanol and then separated into methanol soluble and a methanol insoluble fractions. Collected in Table 10 are the data obtained from these experiments.

In all cases shown, the molecular weight of the products was low. The precipitated oligomer from methanol is more viscous than the methanol soluble oligomer. However, both oligomers have similar ${ }^{1} \mathrm{H}$ NMR, gas chromatograms and mass spectra. The ${ }^{1} \mathrm{H}$ NMR spectra of the products is complex, however, the presence of endo cyclic double bonds could be observed, but exo cyclic double bonds present in the monomer are nearly gone. The endo/exo ratio in the products were approximately $7-8 / 1$. The calculated ratio between the protons on the carbon atoms of the endo cyclic double bonds (4.9-5.7 ppm) and all the methylene and methyl protons (0.6-2.2 ppm) in the repeating unit of the desired polymer is 1:15. However, the ratio obtained was usually 1:20-30. These results suggest that the oligomers obtained possess nearly one endo cyclic double bond per repeating unit. Previous workers using traditional Lewis catalysts were unable to obtain oligomers with as high a double bond content. $6-11$

The mass spectral analysis of both of the polymer fractions show that dimers corresponding to a mass of 272 are the major products of the reaction. We suggest that the either of the two structures shown below may correspond to that of the dimers which have been obtained. 

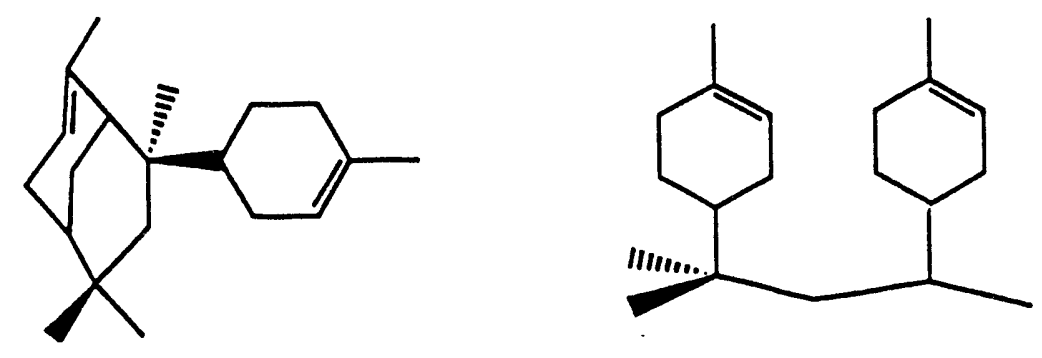

At the present time, we do not have sufficient information to determine which structure is correct, however, NMR studies are in progress to resolve this question.

$\alpha$-Terpinene contains two endocyclic conjugated double bonds. We have carried out the conversion of $\alpha$-terpinene to ascaridole by the dye sensitized photooxidation according to the method of Schenk.12 This is an extremely facile conversion which could be carried out using ambient sunlight and air. No other synthetic oxidant is required. Rearrangement of ascaridole by thermal cleavage of the dioxygen bridge can then be accomplished to give the diepoxide, isoascaridole. Alternatively, the rearrangement may be catalyzed using cobalt tetraphenylporphyrin. These transformations are shown in the following equation.

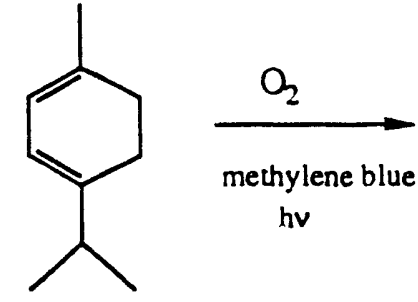

$\alpha$-terpenine

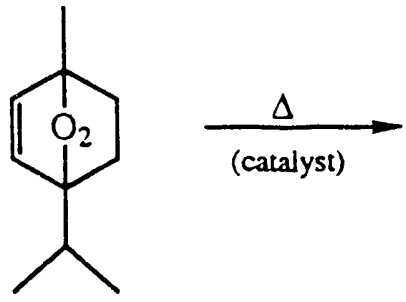

ascaridole

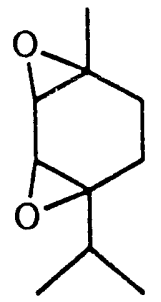

isoascaridole

We have now successfully carried out the above sequence of reactions and are beginning to study the photopolymerization of this monomer. Since, the cationic polymerization of 1,3-diepoxides has not been studied, we elected to carry out a brief preliminary investigation of the photoinduced polymerization of 1,3butadienedioxide. This polymerization proceeds rapidly and 
efficiently to give a crosslinked polymer as shown below in the equation.
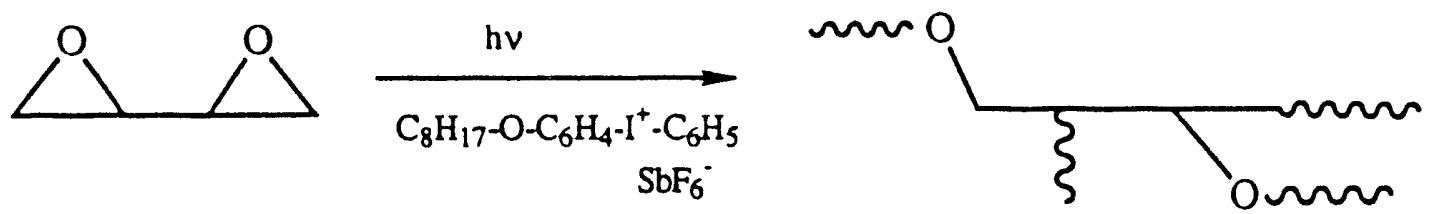

One can conclude after this preliminary study that the 1,3-diepoxide is indeed. very reactive for photoinitiated cationic polymerization and that the two epoxide groups appear to undergo polymerization as independent functional groups.

Polyterpenes occur extensively in nature. Squalene is such a polyterpene containing six repeating isoprene units which has been isolated from shark liver oil and from many other sources. The epoxidation of squalene has been carried out using the phase transfer method developed above for botanical oils.<smiles>CC(C)=CCC/C(C)=C/CC/C(C)=C/CC/C=C(\C)CC/C=C(\C)CCC=C(C)C</smiles>

squalene

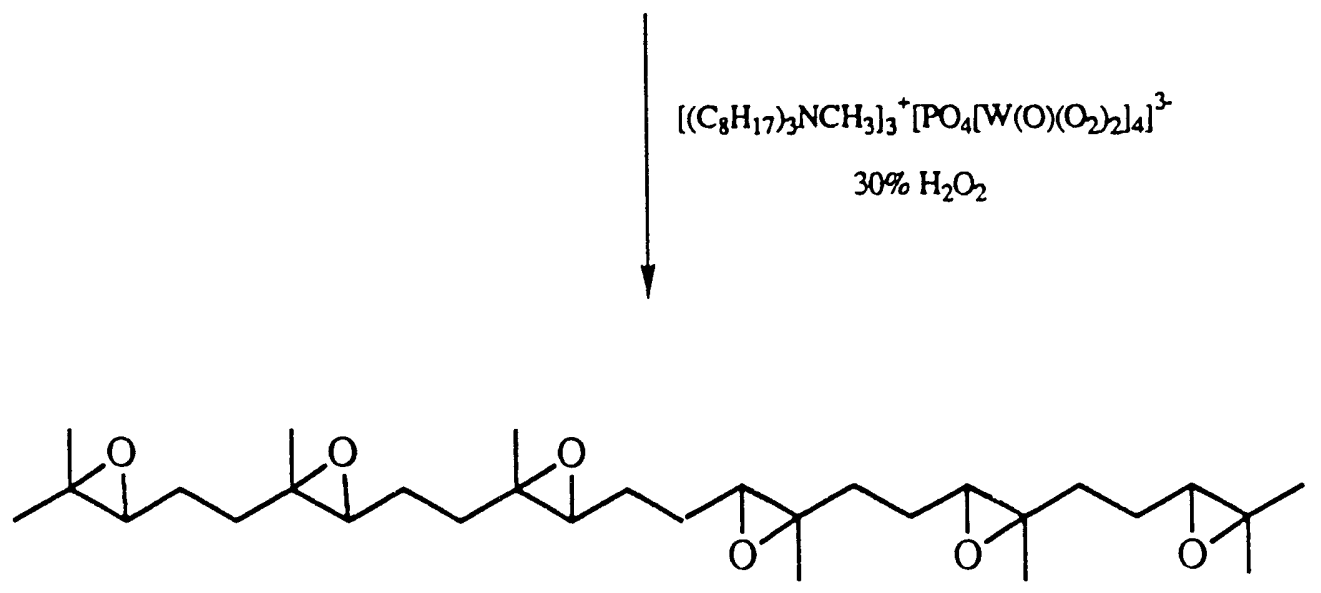


Epoxidation proceeds smoothly to give the hexaepoxide shown in the above equation. The reaction was carried out on a $25 \mathrm{~g}$ scale and high yields of squalene hexaepoxide was obtained. This compound was examined as a monomer for cationic photopolymerization. Using $3 \%$ by weight of (4-dodecyloxyphenyl)phenyliodonium hexafluoroantimonate, it was found that this compound undergoes efficient polymerization using $200 \mathrm{~W}$ Fusion Systems Laboratory UV Irradiator.

Natural rubber (cis and trans poly(isoprene)) is a polyterpene related to squalene which contains one double bond per repeating unit. Poly(isoprene) occurs naturally in a wide number of plants. Historically, the iices of the tropical species Hevea have been cultivated for many years and remains the largest natural source of this material. However, many other temperate and semitropical North American plants have been and are continuing to be developed as a source of poly(isoprene). Among these plant sources are dandelions, gauyule and euphorbae.

It appeared of some interest to examine the possibility of introducing epoxy groups into the backbone of rubber and then photochemically vulcanizing or crosslinking it using cationic photoinitiators. With these considerations in mind, the Malaysian Rubber Producers Association was contacted and samples of epoxidized natural rubber was obtained. For some time, this organization has been trying to find some uses for these materials. Two materials were received having respectively, 25 and 50\% epoxidation of the double bonds. It was found that the sample with $50 \%$ epoxidation was not completely soluble in common solvents and that many gel particles were present. However, the sample bearing $25 \%$ epoxy groups was nicely soluble in dichloromethane as well as a variety of other solvents. Thus, a solution containing $2.0 \mathrm{~g}$ of epoxidized rubber was dissolve; in $25 \mathrm{~mL} \mathrm{CH}_{2} \mathrm{Cl}_{2}$ and $3 \%$ by weight (4-dodecyloxyphenyl)phenyliodonium hexafluoroantimonate added. Films of this solution were cast using drawblades and the films air 
dried to remove the solvent. When the films were irradiated using UV light (Fusion Systems $200 \mathrm{~W}$ Lamp), crosslinking of the rubber was noted. The film hardened considerably after irradiation and was no longer soluble in $\mathrm{CH}_{2} \mathrm{Cl}_{2}$. The following equation expresses the results which were obtained.

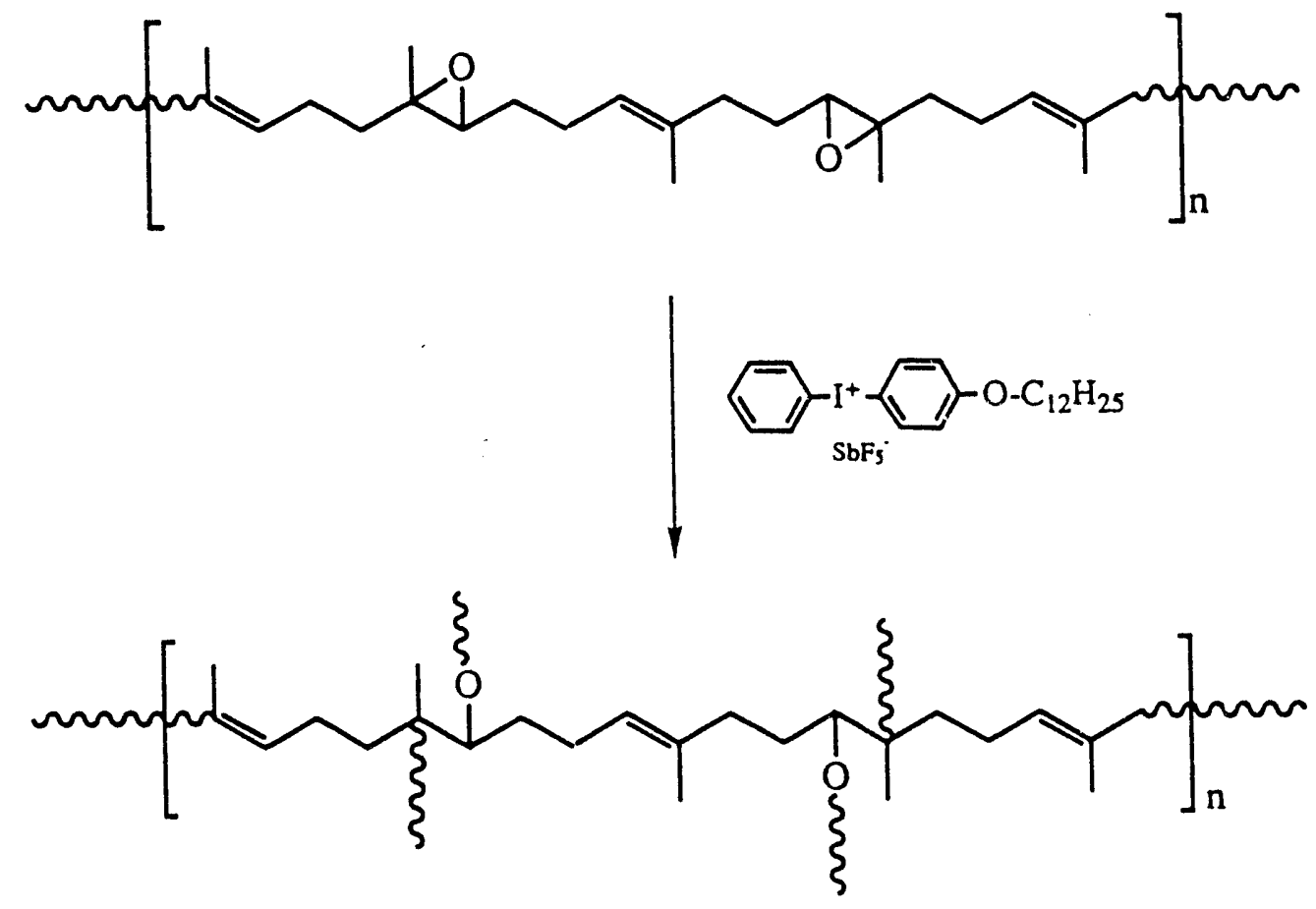

Based on these results, other films were subjected to an imagewise exposure. After washing with $\mathrm{CH}_{2} \mathrm{Cl}_{2}$, it was observed that the nonirradiated portions of the film could be removed selectively whilc those portions of the film which were exposed to the UV irradiation became insoluble.

With these results in hand, we are currently examining the possibility of carrying out the phase transfer catalyzed epoxidation of natural rubber. Using this method, it should be possible to prepare a wide variety of materials having variable epoxide contents. This will allow the design of photocrosslinkable (photovulcanizable) elastomers with different hardnesses, elongations and chemical resistance. The potential also exists to use such materials for the 
rubber modification of conventional epoxide resins to combat the natural brittleness of these materials.

There are many uses for such polymers. Specifically, imageable elastomers have applications as photoresists for electronic and microelectronic applications. Cyclized rubber crosslinked by bisnitrenes generated from the photolysis of bisazides has been widely used for many years as a microelectronic photoresist. Photosensitive elastomers are also of some potential interest as repairable microelectronic encapsulations and for flexographic printing plates.

\section{Acknowledgement}

We would like especially to thank Dr. K.D. Carlson of the Northern Regional Research Center of the U.S. Department of Agriculture for kindly supplying us with crambe, lesquerella, and rapeseed oils. We are also indebted to Mr. D.S. Nelson of the Oregon Meadowfoam Growers Association for his gift of meadowfoam oil. Lastly, Vernonia Galamensis oil was provided by the Performance Resins and Coatings Division of Rhone-Poulenc.

\section{References}

1. J.V. Crivello, J.L. Lee, J. Polym. Sci., Polym Chem. Ed., 27, 3951 (1989).

2. S.R. Akhtar, J.V. Crivello and J.L. Lee, J. Org. Chem., 55, 4222 (1990).

3. K.D. Carlson and S.P. Chang, J. Am. Oil Chemists. Soc., 62 (5), 934 (1985).

4. C. Venturello and R. D'Aloisio, J. Org. Chem., 53, 1553 (1988). 
5. A.M. Rozhkov, Izvest. Sibir. Otdel. Akad. Nauk. S.S.S.R., 723 (1958) (CA 53: 12734c, i958)

6. W.J. Roberts and A.R. Day, J. A.m. Chem. Soc., 72,12?6 (1950).

7. Y. Ohara and H. Okitsu, Jpn. Kokai Tokkyo Koho JP 62 18,407[87 18,407] (CA 107: 17693v).

8. T. Akawa, I. Shiihara, and Y. Hiraga, Japan 73 36,945 (CA 81: 78946e).

9. M. Modena, R.B. Bates and C.S. Marvel, J. Polym. Sci., Part A, 3, 949 (1965).

10. C.S. Marvel, J.R. Hanley, Jr., and D.T. Longone, J. Polym Sci., 11, 551 (1959).

11. T. Aikawa, I Shiihara and N. Kobata, Japan 73 36,944 (CA 81: $78523 q)$.

12. G.O. Schenk and K. Ziegler, Naturwissenschaften, 32,157 (1944). 
Table 1

Structure and Solubility of Onium Salt Photoinitiators

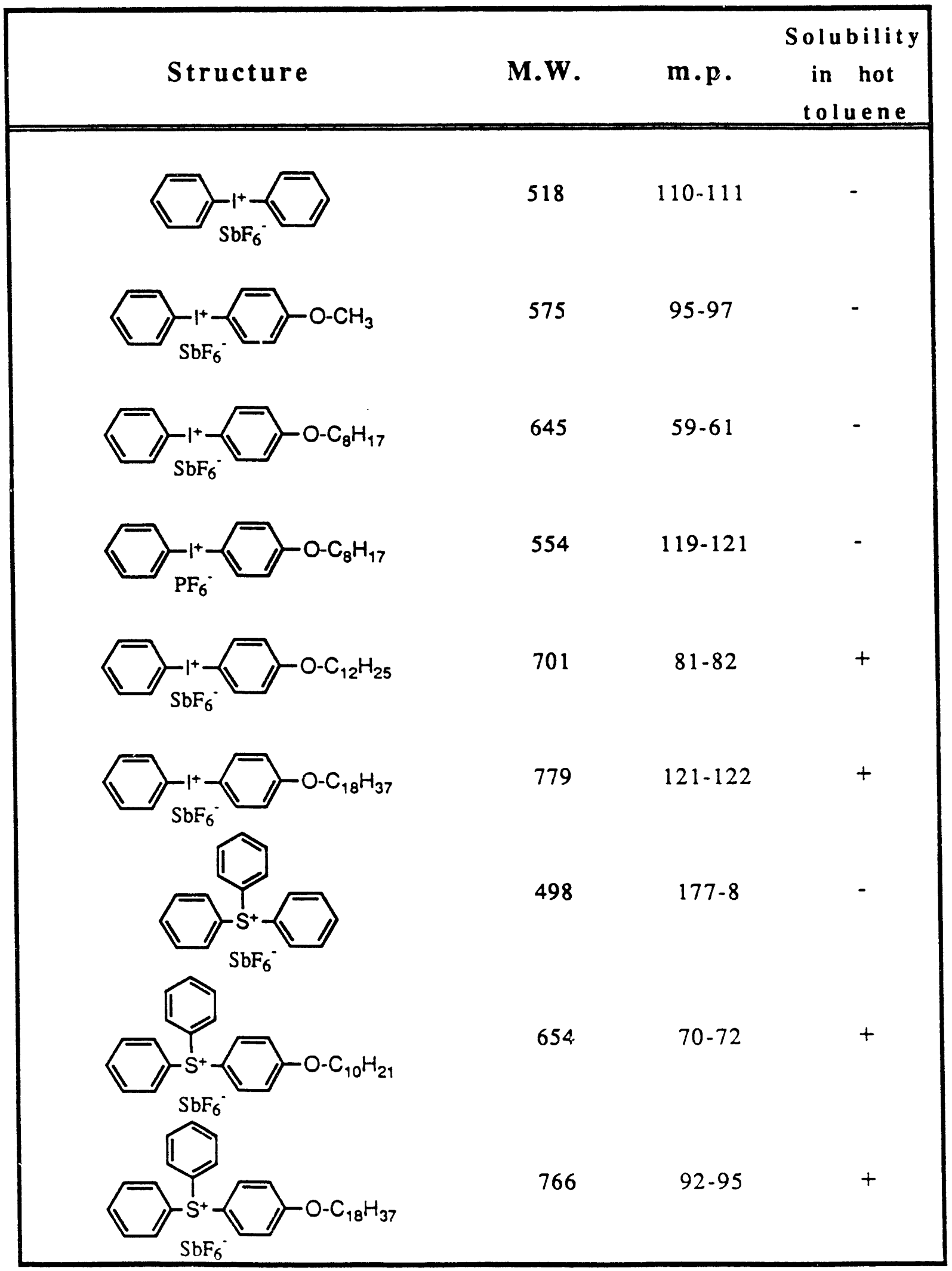


Table 2

Mechanical Properties of UV Cured Vernonia Galamensis Oil*

\begin{tabular}{|c|c|}
\hline Property & Value \\
\hline Pencil Hardness & $6 \mathrm{H}$ \\
\hline Rocker Hardness & $20-30$ \\
\hline Adhesion & $5 B$ \\
\hline \multicolumn{2}{|l|}{ Impact Strength } \\
\hline Direct & $>160 \mathrm{lb}-\mathrm{in}$ \\
\hline Reverse & $>160$ lb-in \\
\hline Flexibility (1/8 " mandrel) & excellent \\
\hline
\end{tabular}


Table 3

Commercially Available Epoxy Oils

\section{Material}

Designation

Epoxidized soybean oil (Drapex 6.8, Witco Chem. Co.)

I

Epoxidized linseed oil (Drapex 10.2, Witco Chem. Co.)

I I

Vernonia oil (Rhone-Poulenc)

I I I

Epoxidized linseed oil (Vikoflex 7190, Atochem Co.)

IV

Epoxidized linoleic dimer acid (Atochem Co.)

V

Aliphatic glycidyl ether (Atochem Co.)

V I 
Table 4

UV Cure of Commercially Available Epoxidized Natural Pruducts

\begin{tabular}{|c|c|c|c|c|}
\hline No. & Type of Oil & $\begin{array}{l}\text { Photo- } \\
\text { initiator }\end{array}$ & $\begin{array}{l}\text { \% Photo- } \\
\text { initiator }\end{array}$ & $\begin{array}{l}\text { Cure Speed } \\
(\mathrm{ft} / \mathrm{min})\end{array}$ \\
\hline 1. & I & VII & 1 & 25 \\
\hline 2. & I & VII & 3 & 25 \\
\hline 3. & I & VII & 5 & 25 \\
\hline 4. & I & VIII & 1 & 25 \\
\hline 5. & I & VIII & 3 & 25 \\
\hline 6. & I & VIII & 5 & 26 \\
\hline 7. & I I & VII & 1 & 25 \\
\hline 8. & I I & VII & 3 & 44 \\
\hline 9. & I I & VII & 5 & 46 \\
\hline 10. & I I & VIII & 1 & 45 \\
\hline 11. & II & VIII & 3 & 45 \\
\hline 12. & I I & VIII & 5 & 46 \\
\hline 13. & III & VII & 1 & 25 \\
\hline 14. & III & VII & 3 & 44 \\
\hline
\end{tabular}




\begin{tabular}{|c|c|c|c|c|}
\hline 15. & II I & VII & 5 & 46 \\
\hline 16. & II I & VIII & 1 & 28 \\
\hline 17. & II I & VIII & 3 & 29 \\
\hline 18. & III & VIII & 5 & 42 \\
\hline 19. & IV & VII & 1 & 16 \\
\hline 20. & IV & VII & 3 & 23 \\
\hline 21. & IV & VII & 5 & 40 \\
\hline 22. & IV & VIII & 1 & 12 \\
\hline 23. & IV & VIII & 3 & 24 \\
\hline 24. & IV & VIII & 5 & 34 \\
\hline 25 & V & $\begin{array}{l}\text { No cl } \\
\text { up to } \\
\text { with }\end{array}$ & $\begin{array}{l}\text { at } \\
\text { esid } \\
\text { iatc }\end{array}$ & $\begin{array}{l}\text { t velocity or } \\
\text { UV chambe: }\end{array}$ \\
\hline 26. & VI & VII & 1 & 7 \\
\hline 27. & VI & VII & 3 & 8 \\
\hline 28. & VI & VII & 5 & 10 \\
\hline 29. & VI & VIII & 1 & 8 \\
\hline 30. & VI & VIII & 3 & 9 \\
\hline 31. & VI & VIII & 5 & 11 \\
\hline
\end{tabular}


Table 5

Effect of the Length of the Side Chain of the Photoinitiator on the UV Cure of Epoxidized Linseed Oil*<smiles>[R]Oc1ccc([I+]c2ccccc2)cc1</smiles>

\begin{tabular}{|c|c|c|}
\hline $\mathbf{R}$ & Wt. Photoinitiator & Cure Rate (ft/min) \\
\hline $\mathrm{CH}_{3}$ & 0.150 & 39 \\
$\mathrm{t}-\mathrm{C}_{4} \mathrm{H}_{9}$ & 0.162 & 31 \\
$\mathrm{C}_{8} \mathrm{H}_{17}$ & 0.178 & 34 \\
$\mathrm{C}_{10} \mathrm{H}_{21}$ & 0.186 & 34 \\
$\mathrm{C}_{11} \mathrm{H}_{23}$ & 0.190 & 34 \\
$\mathrm{C}_{14} \mathrm{H}_{29}$ & 0.202 & 37 \\
$\mathrm{C}_{16} \mathrm{H}_{33}$ & 0.210 & 37 \\
$\mathrm{C}_{18} \mathrm{H}_{37}$ & 0.218 & 38 \\
\hline
\end{tabular}

*Solutions prepared with $3.0 \mathrm{~g}$ epoxidized linseed oil and drawn as 1 mil films on glass plates. UV cure was performed using a $300 \mathrm{~W}$ Fusion Systems lamp. 
Table 6

A Comparison of the Properties of Sunflower Oil Epoxidized by Different Methods

\begin{tabular}{|l|c|c|c|}
\hline Method & Iodine No.* & Epoxy No. & Yield (\%) \\
\hline A & 1.28 & 7.53 & 95 \\
B & 4.0 & 6.3 & 95 \\
\hline
\end{tabular}

*Iodine number measured after epoxidation. 
Table 7

Characteristics of Various Epoxidized Botanical Oils

\begin{tabular}{|c|c|c|c|c|c|c|c|}
\hline \multirow[b]{2}{*}{ Epox. Oil } & \multicolumn{2}{|c|}{ Iodine No. ${ }^{a}$} & \multirow{2}{*}{$\begin{array}{c}\text { Av. Mol } \\
\text { Wt. } \\
(\mathrm{g} / \mathrm{mol})\end{array}$} & \multirow[b]{2}{*}{$\mathrm{DB} / \mathrm{mol}^{\mathrm{b}}$} & \multirow[b]{2}{*}{ WPEC } & \multirow[b]{2}{*}{$\begin{array}{l}\text { Epoxy } \\
\text { No.d }\end{array}$} & \multirow[b]{2}{*}{$\begin{array}{l}\text { Meth } \\
\text { odf }^{f}\end{array}$} \\
\hline & $\begin{array}{l}\text { before } \\
\text { epox }\end{array}$ & $\begin{array}{l}\text { after } \\
\text { lon }\end{array}$ & & & & & \\
\hline Soybean & 130.2 & 1.2 & 891.1 & 4.2 & 223.8 & 7.14 & A \\
\hline Crambe & 84.7 & 0.6 & 1026.2 & 3.3 & 307.0 & 5.22 & A \\
\hline Lesquerella & 108.1 & 2.0 & 886.8 & 3.5 & 315.5 & 5.06 & A \\
\hline Rapeseed & 103.3 & 1.8 & 909.0 & 3.5 & 305.5 & 5.24 & A \\
\hline Safflower & 139.3 & 1.5 & 975.1 & 4.9 & 213.6 & 7.49 & A \\
\hline Sunflower & 132.8 & 1.38 & 896.5 & 4.3 & 212.5 & 7.53 & A \\
\hline Sunflower & 132.8 & 4.0 & 896.5 & 4.3 & 255.3 & 6.3 & B \\
\hline Vernonia & 92.1 & 4.1 & 926.0 & 3.4 & 223.2 & 7.17 & B \\
\hline Canola & 119.0 & 0.6 & 1013.0 & 4.4 & 280.0 & 5.71 & B \\
\hline $\begin{array}{l}\text { Meadow- } \\
\text { foam }\end{array}$ & 92.0 & 2.5 & 1025.2 & 3.5 & 2.4 & 8.77 & B \\
\hline
\end{tabular}

aDetermined by the Wij's method (ASTM 1959), bDouble bonds per mole on oil before epoxidation, ${ }^{c}$ Epoxy equivalent weight, dEpoxy content or percent oxirane oxygen after epoxidation (ASTM D1652-88), fEpoxidation method; A, epoxidation using peracetic acid, B, by phase transfer catalysis using tetraalkylammonium peroxotunstic acid catalyst. 
Table 8

UV Cure Studies of Epoxidized Oils

\begin{tabular}{|c|c|c|c|}
\hline Oil & $\begin{array}{c}\text { Epoxy } \\
\text { No. }\end{array}$ & $\begin{array}{c}\text { Cure } \\
\text { speed(ft } \\
\text { /min }\end{array}$ & Remarks \\
\hline Vernonia & 3.89 & 35.3 & clear film, some fish eyes \\
\hline E-Vernonia & 7.17 & $\begin{array}{l}=50^{\circ}- \\
15.6\end{array}$ & Matte film \\
\hline E-Lesquerella & 5.06 & 24.2 & Clear film with fish eyes \\
\hline E-Crambe & 5.23 & 19.4 & Matte film \\
\hline E-Rapeseed & 5.24 & 22.6 & Clear film, with fish eyes \\
\hline $\begin{array}{l}\text { E-Soybean } \\
\text { (Drapex 6.8) }\end{array}$ & 6.65 & 24.0 & Clear film, with fish eyes \\
\hline $\begin{array}{l}\text { E-Soybean } \\
\text { (Vikoflex 7190) }\end{array}$ & 9.03 & 21.0 & Clear film, with fish eyes \\
\hline E-Canola & 5.85 & 25.2 & Clear film, with fish eyes \\
\hline E-Soybean & 7.15 & 31.9 & Clear film \\
\hline E-Safflower & 7.48 & 38.6 & Clear film, with fish eyes \\
\hline E-Sunflower & 7.53 & 40.2 & Matte film \\
\hline $\begin{array}{l}\text { E-Linseed } \\
\text { (Drapex 10.4) }\end{array}$ & 10.41 & 43 & Matte fim \\
\hline
\end{tabular}

*UV cures carried out on 1 mil films using a conveyorized $300 \mathrm{~W}$ Fusion Systems microwave activated mercury arc lamp. 3\% (4-Octyloxyphenyl)phenyliodonium hexafluoroantimonate was used as the photoinitiator. 
Table 9

Ratio of Endo/Exo Cyclic Double Bonds in Poly(d-limonene)

\begin{tabular}{|c|c|c|c|c|c|}
\hline Initiator & Endo(5.2-5.3 & ppm) & Exo & $(4.6-4.7$ & ppm) \\
\hline AIBN & 7 & & & 3 & \\
\hline BPO & 8 & & & 12 & \\
\hline $\mathrm{t}-\mathrm{BuPO}$ & 8 & & & 10 & \\
\hline
\end{tabular}




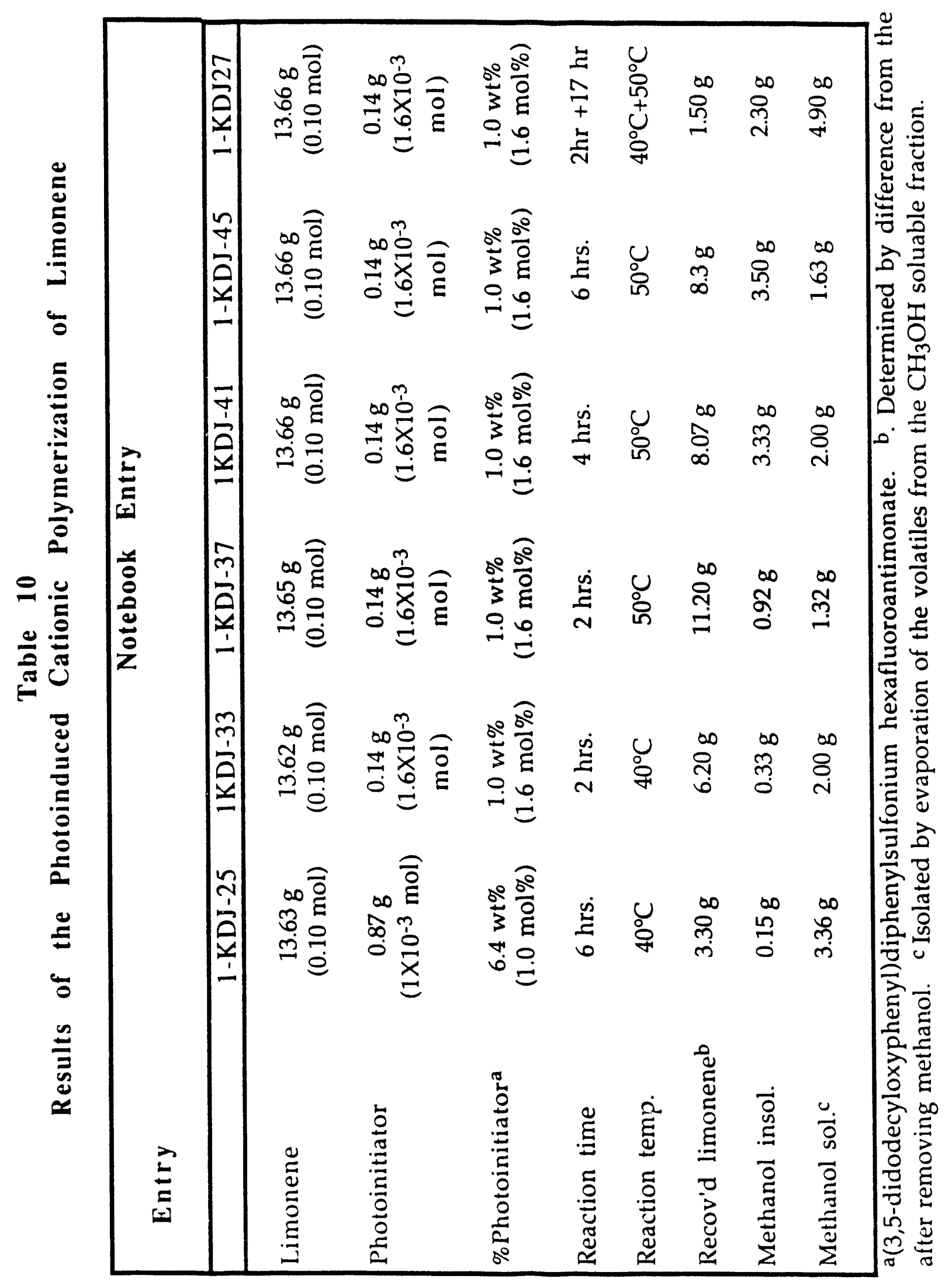




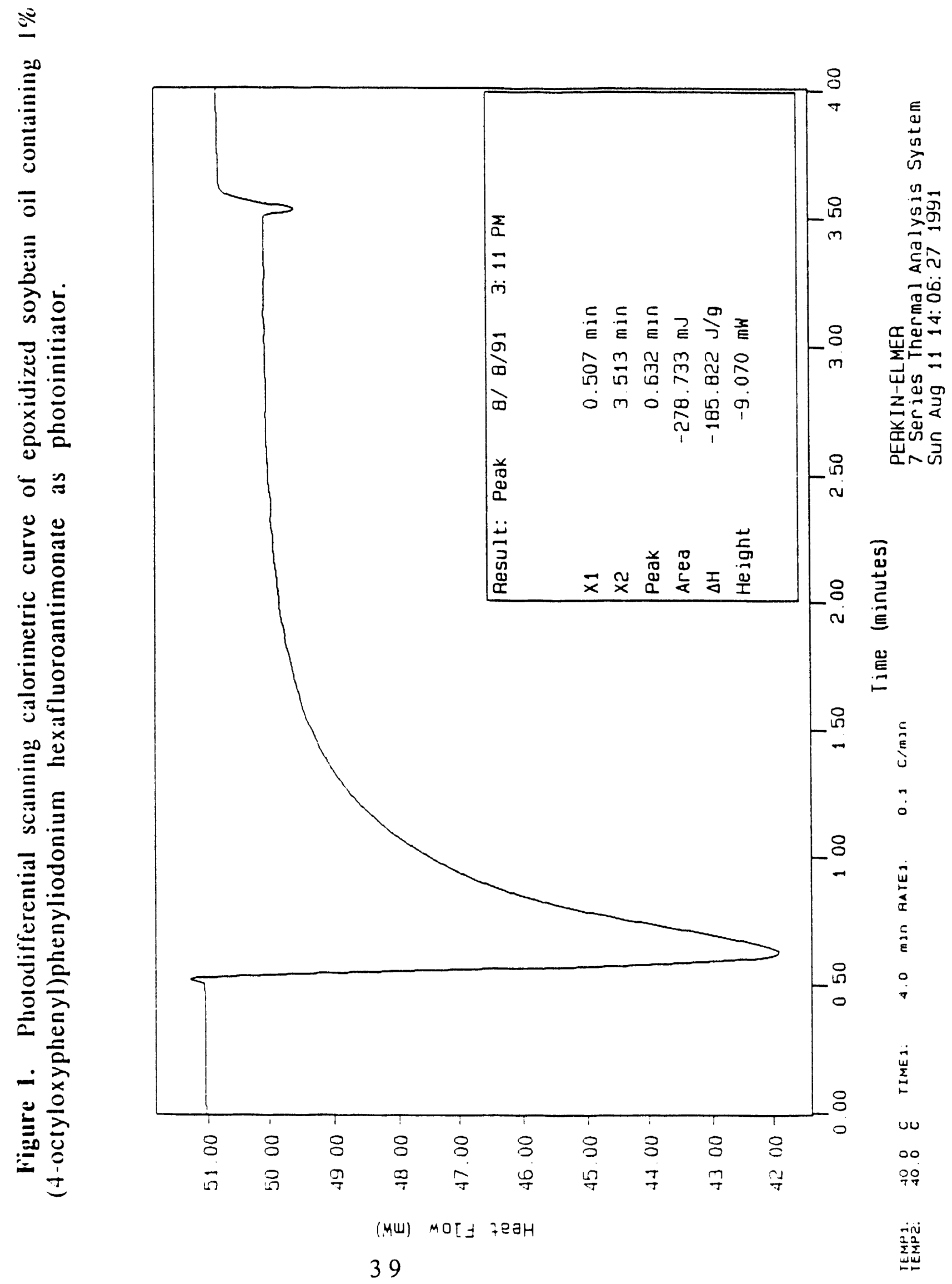


Figure 2

\section{PHOTOINITIATED POLYMERIZATION OF EPOXIDIZED SOY AND LINSEED OILS}

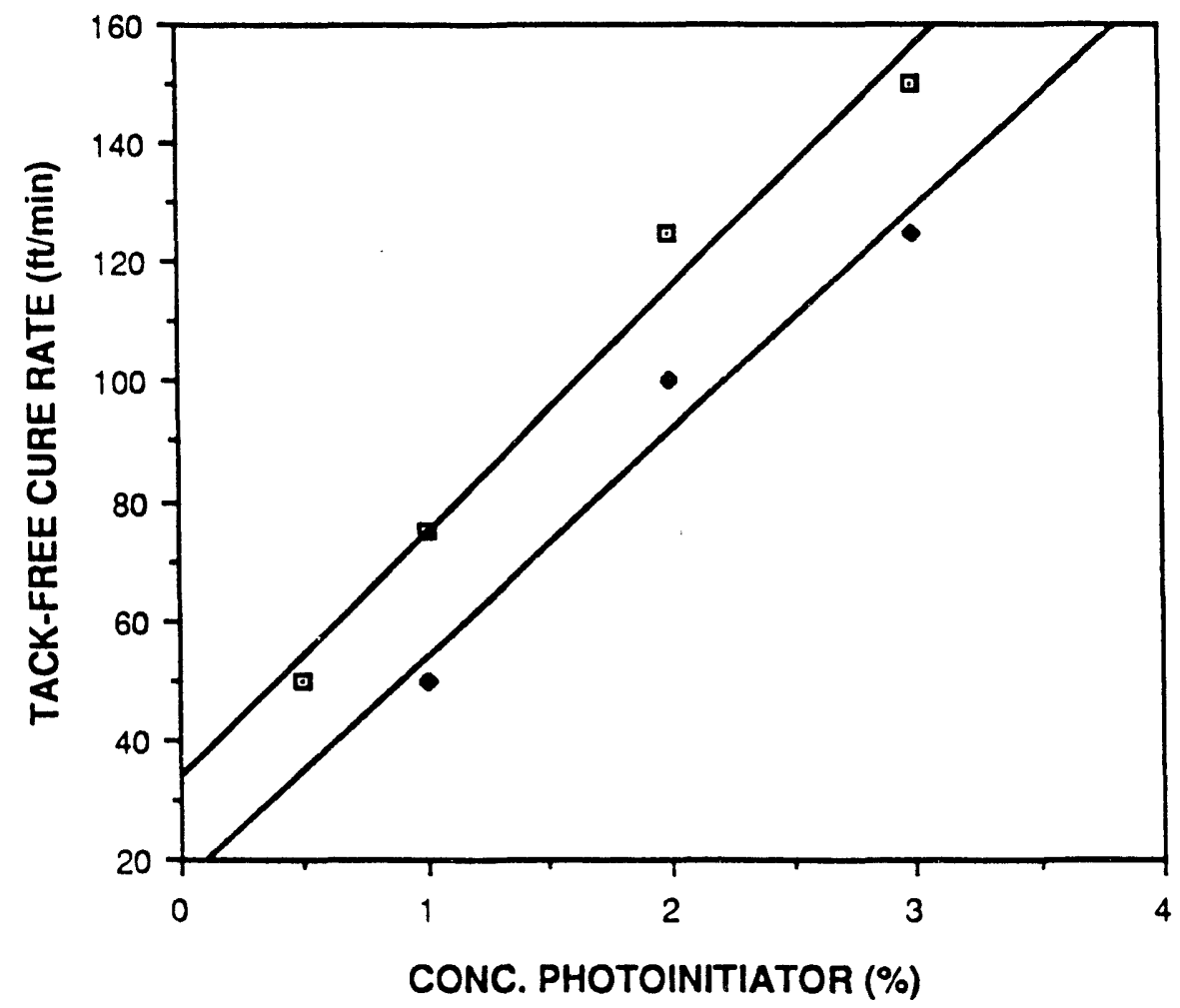

Figure 2 Cure rate of $1 \mathrm{mil}$ films of epoxidized soybean oil ( 1 ) and linseed oil $(\square)$ on glass with various concentrations of diphenyl(decyloxyphenyl)- sulfonium $\mathrm{SbF}_{6}{ }^{-}$. Cures carried out using a PPG UV processor with $2300 \mathrm{~W}$ medium pressure $\mathrm{Hg}$ arc lamps. 
Figure- 3. Soybean oil before (top) and after (bottom) epoxidation by the phase transfer method

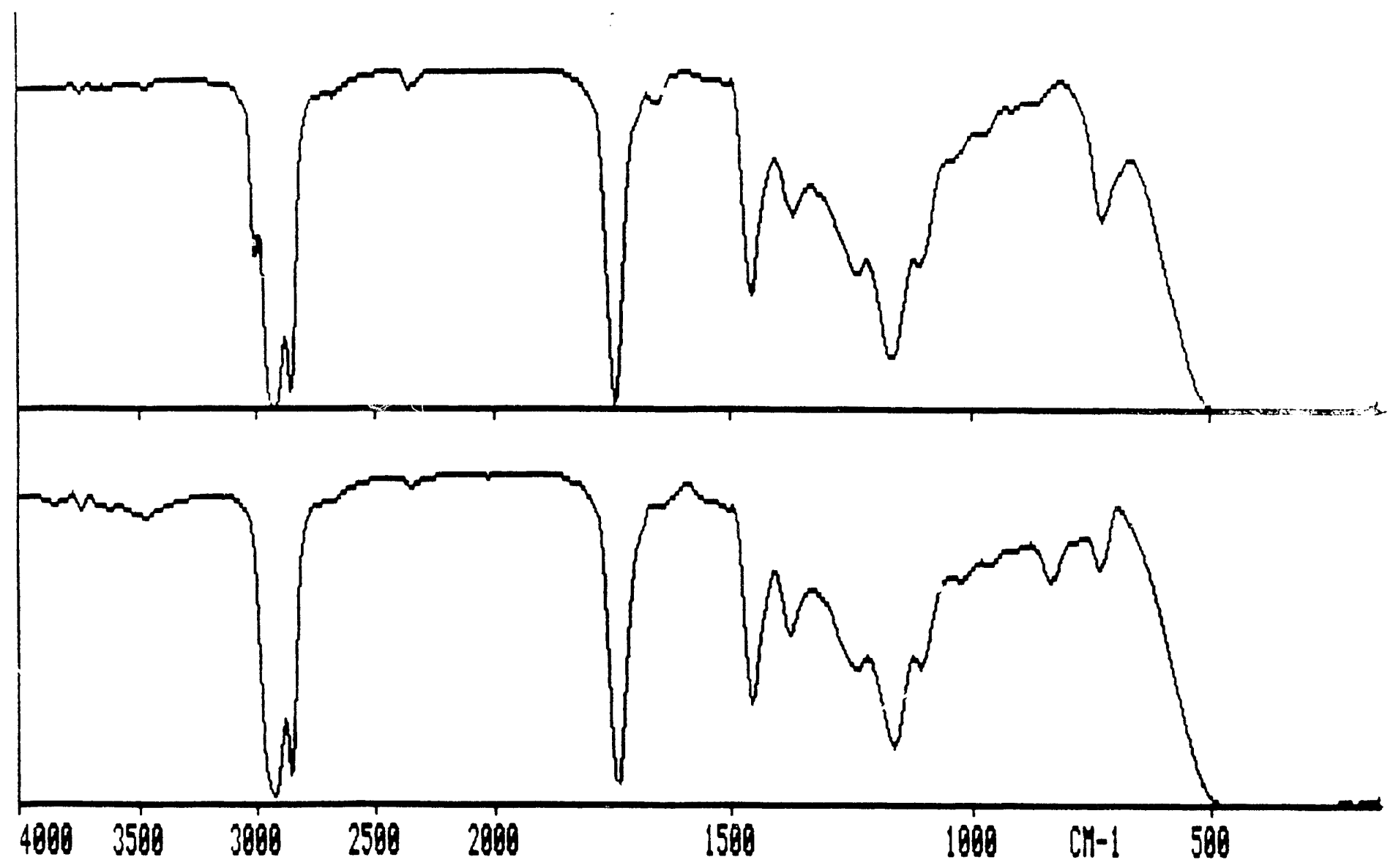



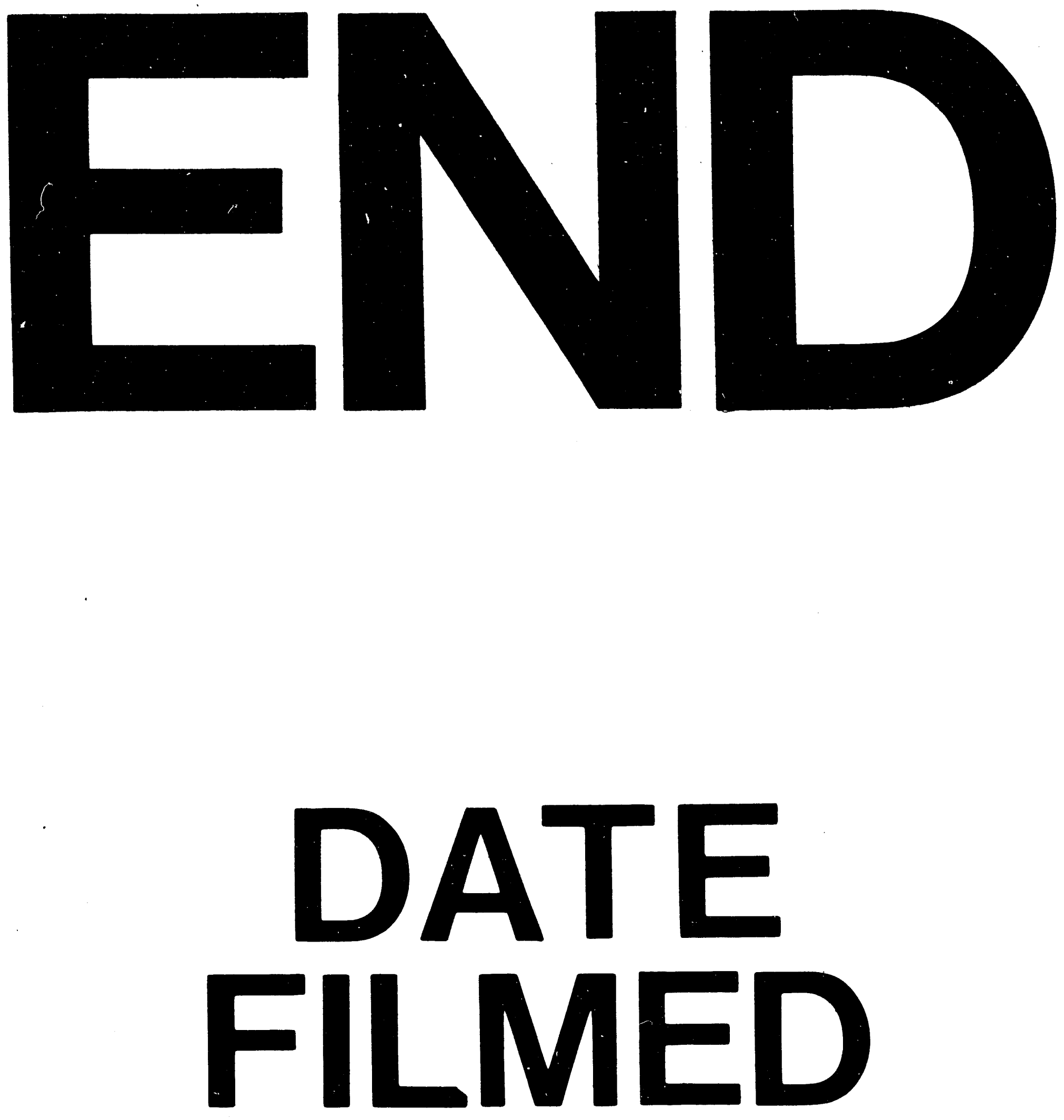

I

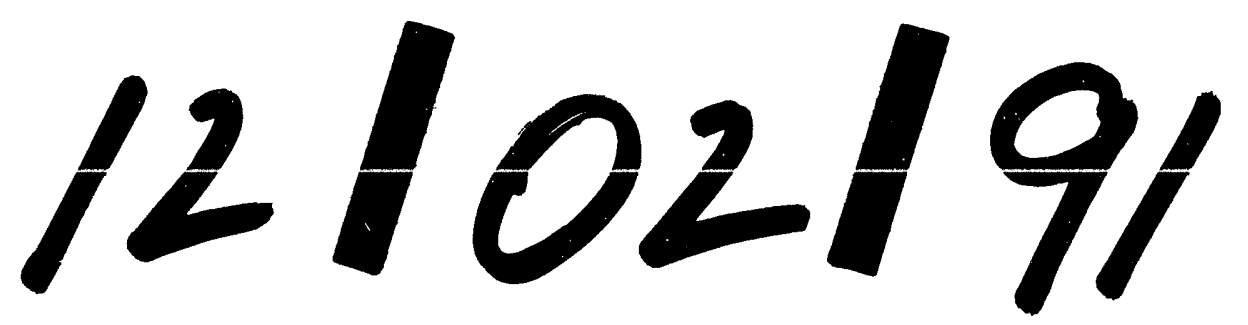


